\title{
In vitro generation of insulin-producing beta cells from adult exocrine pancreatic cells
}

Received: 20 August 2004 / Accepted: 25 October 2004 / Published online: 23 December 2004

C) Springer-Verlag 2004

\begin{abstract}
Aims/hypothesis: Transplantation of insulinproducing beta cells from donors can cure diabetes, but they are available in insufficient quantities. In this study, we investigated the possibility of generating insulinproducing cells from adult rat exocrine cells cultured in the presence of growth factors. Methods: Rat exocrine pancreatic cells were isolated and treated in vitro with epidermal growth factor (EGF) and leukaemia inhibitory factor (LIF). Analysis was performed by immunocytochemistry, DNA measurement and radioimmunoassay. Cells were transplanted to alloxan-treated $(70 \mathrm{mg} / \mathrm{kg})$ nude mice and glycaemia was monitored for 21 days. Nephrectomy was performed on day 15. Results: In a 3-day culture period, addition of LIF plus EGF to the medium resulted in an 11-fold increase of the beta cell mass. This could not be attributed to the very low mitotic activity of contaminating beta cells. Furthermore, when contaminating beta cells were initially destroyed with alloxan, this effect was even more pronounced. The newly formed cells secreted insulin in response to glucose and were immunoreactive for C-peptide-I, Pdx-1 and GLUT-2, which are characteristics of mature beta cells. Electron microscopy showed that they also contained insulinimmunoreactive secretory granules. Some insulin-positive cells were immunoreactive for amylase and cytokeratin20 , or were binucleated, which are characteristics of exocrine cells. The cells were able to restore normoglycaemia when transplanted to alloxan-diabetic mice, and hyperglycaemia recurred upon removal of the graft. Conclusions/interpretation: Our study shows that functional beta cells can be generated from exocrine tissue by transdifferentiation and thereby may offer a new perspective for beta cell therapy.
\end{abstract}

L. Baeyens · S. De Breuck - J. Lardon - J. K. Mfopou

I. Rooman · L. Bouwens $(\bowtie)$

Cell Differentiation Unit, Free University of Brussels,

Laarbeeklaan 103,

1090 Brussels, Belgium

e-mail: lucbo@expa.vub.ac.be

Tel.: +32-2-4774457

Fax: +32-2-4774405
Keywords Beta cell - Diabetes mellitus - Epidermal growth factor - Leukaemia inhibitory factor - Neogenesis · Pancreas $\cdot$ Transdifferentiation

Abbreviations BrdU: 5'-Bromodeoxyuridine - CCKB: Cholecystokinin B - CK20: Cytokeratin 20 - EGF: Epidermal growth factor - FBS: Fetal bovine serum . GLUT2: Glucose transporter 2 - IAPP: Islet amyloid polypeptide - LIF: Leukaemia inhibitory factor - NOD: Nonobese diabetic

\section{Introduction}

Islet transplantation can restore functional beta cell mass in diabetic patients [1], but it is seriously hampered by the shortage of donor tissue. This problem could be solved by finding ways of generating more islet cells from the available pancreatic tissue, by the process of neogenesis $[2,3]$ or by stimulating proliferation of beta cells [4]. Despite much progress in our understanding of pancreas development during the last decade, the extracellular factors that specify islet cell differentiation in the embryo remain unknown [5]. In adult mammals, the endocrine pancreas can expand or regenerate under certain experimental conditions, either as a result of islet cell proliferation [4], or neogenesis from progenitor cells [3, 6-8]. In vitro, very few studies have been able to demonstrate the feasibility of inducing islet neogenesis from adult tissue. In cultures derived from human pancreas that were treated with keratinocyte growth factor and nicotinamide, increases in insulin content were noted over a 3- to 4-week period and morphological observations suggested that islet cells budded from cell monolayers under the influence of extracellular matrix [9]. The precursors responsible for this "neogenesis" were characterised as cells expressing the ductal marker cytokeratin-19 [10]. However, the number of insulin-producing cells obtained in this study was limited. Long-term cultures obtained from nonobese diabetic (NOD) mouse pancreas under glucose-free conditions, generated additional islet-like structures in the 
presence of glucose [11]. However, these cells didn't reach functional maturity in vitro. It is at present unclear whether the latter observations may have been due to "passenger" stem cells derived from the blood circulation, which have been discovered recently in NOD mice [12].

We have shown that differentiated exocrine cells can revert to a partially dedifferentiated state with the capacity to transdifferentiate into different phenotypes, including ductal cells $[13,14]$, hepatocyte-like cells $[15]$ and insulinpositive cells [16]. This suggests that exocrine cells, which represent the great majority of cells in this organ, can be used to generate endocrine cells under the appropriate conditions.

Based on the similarities that exist between embryonic neurogenesis and pancreatic endocrinogenesis at the level of fate-specifying transcription factors, we wanted to know whether extrinsic signals known to regulate neural development and regeneration can also affect pancreatic islet regeneration. For the present study, we tested in primary cultures derived from adult rat pancreas the effect of leukaemia inhibitory factor (LIF) and epidermal growth factor (EGF), signals known to play a key role in neural development and regeneration.

\section{Materials and methods}

Animals Male 10- to 12-week-old Wistar rats (Janvier, Le Genest-St-Isle, France) weighing 250 to $300 \mathrm{~g}$ were used for the isolation of cells from the pancreas. Eight-week-old male BALB/c nude mice (Charles River Laboratories, Wilmington, MA, USA) weighing 22 to $24 \mathrm{~g}$ were used as recipients for transplantation. All animal experimentation was approved by the Ethical Committee of the Free University of Brussels.

Isolation of exocrine tissue Pancreata were partially dissociated with collagenase and exocrine acini were purified by centrifugal elutriation as published before $[13,14]$.

Culture procedure Exocrine cells were precultured for 4 days in bacteriological Petri dishes (Nunc, Naperville, IL, USA) in suspension culture in RPMI-1640 Glutamax-I medium supplemented with $10 \%$ fetal bovine serum (FBS; Gibco BRL, Paisley, Scotland), penicillin $(75 \mathrm{mg} / \mathrm{l})$ (Continental Pharma, Brussels, Belgium) and streptomycin (100 mg/l) (Sigma, St Louis, MO, USA). Geneticin sulphate $(50 \mu \mathrm{g} / \mathrm{ml})$ (Sigma) was used to keep fibroblasts out of the culture. The medium was replaced daily during this preculture period. On the 4th day after isolation, cells were distributed in 1,000- $\mu$ l aliquots over 24-well plates (Falcon; BD Biosciences, Erembodegem, Belgium). This procedure was standardised so as to obtain approximately 75 ng DNA per well. For some experiments, the cells were treated with $10 \mathrm{mmol} / \mathrm{l}$ alloxan for $10 \mathrm{~min}$ prior to plating. After overnight culture, nonadherent cells were washed off and then either control medium or medium containing growth factor was added to the wells. Control medium consisted of RPMI-1640 medium supplemented with $1 \%$
FBS and antibiotics (streptomycin $0.1 \mathrm{~g} / 1$ and penicillin $0.075 \mathrm{~g} / \mathrm{l})$. Growth factor medium consisted of control medium supplemented with $50 \mathrm{ng} / \mathrm{ml}$ human recombinant EGF (Sigma) and $40 \mathrm{ng} / \mathrm{ml}$ recombinant mouse LIF (Sigma). Cell monolayers were analysed after a culture period of 3 days in the latter media.

Immunocytochemistry and DNA measurement The amount of cells per well was measured by a DNA fluorimetric assay based on the binding of Hoechst 33258 dye [17]. At least 6 wells were used per experimental condition, so that triplicate cultures could be used for DNA-extraction and, in parallel, for immunocytochemical analysis of cell composition. Immunocytochemical staining of the monolayers was performed directly in the 24 -well plates. For this purpose, the cell monolayers were fixed for $10 \mathrm{~min}$ with $4 \%$ buffered formaldehyde followed by $20 \mathrm{~min}$ methanol $\left(-20^{\circ} \mathrm{C}\right)$ for cell permeabilisation. For single staining of only one antigen, we used the streptavidinbiotin peroxidase method $[18,19]$. For double staining, we used the indirect method with FITC- and TRITC-labelled secondary antibodies (Jackson Immunoresearch, West Grove, PA, USA). Primary antibodies used in this study are polyclonal anti-insulin (C. Van Schravendijk, Vrije Universiteit Brussel, Belgium) [18, 19], polyclonal anti-rat C-peptide-I (O. D. Madsen, Hagedorn Research Institute, Gentofte, Denmark) [20], polyclonal anti-Pdx1 (O. D. Madsen) [13], polyclonal anti-GLUT-2 (Wak-Chemie, Bad Soden, Germany), monoclonal anti-cytokeratin-20 (CK20) (Novocastra, Newcastle-upon-Tyne, UK) [18, 19], polyclonal anti-alpha-amylase (Sigma), polyclonal anti-chromogranin-A (Biogenex, San Ramon, CA, USA) and mouse monoclonal anti-BrdU (ICN, Irvine, CA, USA). To assess the incorporation of 5'-bromodeoxyuridine (BrdU) by proliferating cells, we added $10 \mu \mathrm{mol} / \mathrm{l} \mathrm{BrdU}$ (Sigma) to the culture medium $1 \mathrm{~h}$ before fixation [14].

For BrdU pulse-chase labelling, BrdU was added to the culture medium on the first day of adherent cell culture and removed $24 \mathrm{~h}$ later. The cells were analysed $24 \mathrm{~h}$ after the pulse or on day 3 of cell culture, i.e., after $48 \mathrm{~h}$ chasing in the absence of BrdU. BrdU incorporation was scored both in insulin-expressing cells and in cytokeratinexpressing cells.

Immuno-gold labelled electron microscopy was performed as described previously [21].

Morphometry We used computer-assisted morphometry [18] to measure the area of monolayers in 24-well plates.

Insulin measurements Cellular insulin content and insulin released in the medium were measured by radioimmunoassay [22]. To study glucose-stimulated insulin release, insulin in the culture medium was measured after a 4-h incubation period in basal medium containing $2.5 \mathrm{mmol} / \mathrm{l}$ glucose, followed by $4 \mathrm{~h}$ of incubation in $20 \mathrm{mmol} / \mathrm{l}$ glucose (serum- and glutamine-free HAM-10 medium; Gibco) [23]. 
Transplantation To transplant the monolayer cells, they were cultured on collagen S from calf skin (type I; Roche Molecular Biochemicals, Mannheim, Germany) and detached with collagenase P (Roche Molecular Biochemicals). Under mild anaesthesia with ketamine $(75 \mathrm{mg} / \mathrm{kg})$ and a mixture of medetomidine, methyl-parahydroxybenzoate and propyl-parahydroxybenzoate $(1 \mathrm{mg} / \mathrm{kg})$ nude mice were injected intravenously with $70 \mathrm{mg} / \mathrm{kg}$ alloxan $3 \mathrm{~h}$ prior to transplantation. Mice were then anaesthetised with ketamine $(75 \mathrm{mg} / \mathrm{kg})$ and a mixture of medetomidine, methyl-parahydroxybenzoate and propyl-parahydroxybenzoate $(4 \mathrm{mg} / \mathrm{kg})$ and cell pellets of 50,000 to 100,000 insulin-positive cells were implanted under the kidney capsule [24]. Blood glucose levels were monitored in samples obtained from the tail vein of fed mice by using Glucocard Memory strips (A. Menarini Diagnostics Benelux, Zaventem, Belgium).

Statistics We used a two-tailed, paired Student $t$ test and considered a confidence interval of less than 0.05 to be statistically significant. Values are given as means \pm SEM. The number of independent experiments is indicated in the text.

\section{Results}

We isolated and precultured exocrine acinar cell aggregates as described earlier [13, 14] and subsequently allowed these cells to form monolayers on plastic. More than $90 \%$ of the cells were immunoreactive for the ductal marker CK20 (Fig. 1a) and had lost the amylase marker of acinar cells (data not shown). Of these cells, $79.0 \pm 0.4 \%$ $(n=7)$ were binucleated, a characteristic of part of the acinar cells. These cultures were initially contaminated with $3.7 \pm 0.46 \%(n=7)$ insulin-positive cells.

When monolayer cultures were treated with LIF and EGF for 3 days, we noted a significant increase in DNA content compared to the start of the culture and compared to cultures devoid of both growth factors (Fig. 2a). The total surface covered with cells which was measured by morphometry showed a comparable increase (not shown).

Treatment with LIF and EGF also induced a significant increase in the frequency of insulin-positive cells, expressed as the percentage of all cells (Fig. 2b). When multiplying the frequency of insulin-positive cells by total DNA content to have a measure of the beta cell mass, we observed an 11-fold increase in beta cell mass in the presence of LIF and EGF over the 3-day culture period (Fig. 2c). Analysis of total cellular insulin content by radioimmunoassay showed a sixfold increase in LIF and EGF-treated cultures compared to control cultures (Fig. 2d).

In a more stringent approach, we pretreated the cultures with alloxan to remove contaminating beta cells prior to monolayer formation. Initially, these preparations contained $0.3 \pm 0.1 \%$ insulin-positive cells. After 3 days of culture of the monolayers in the presence of LIF and EGF, we found $9.2 \pm 1.5 \%$ insulin-positive cells $(n=5)$, whereas
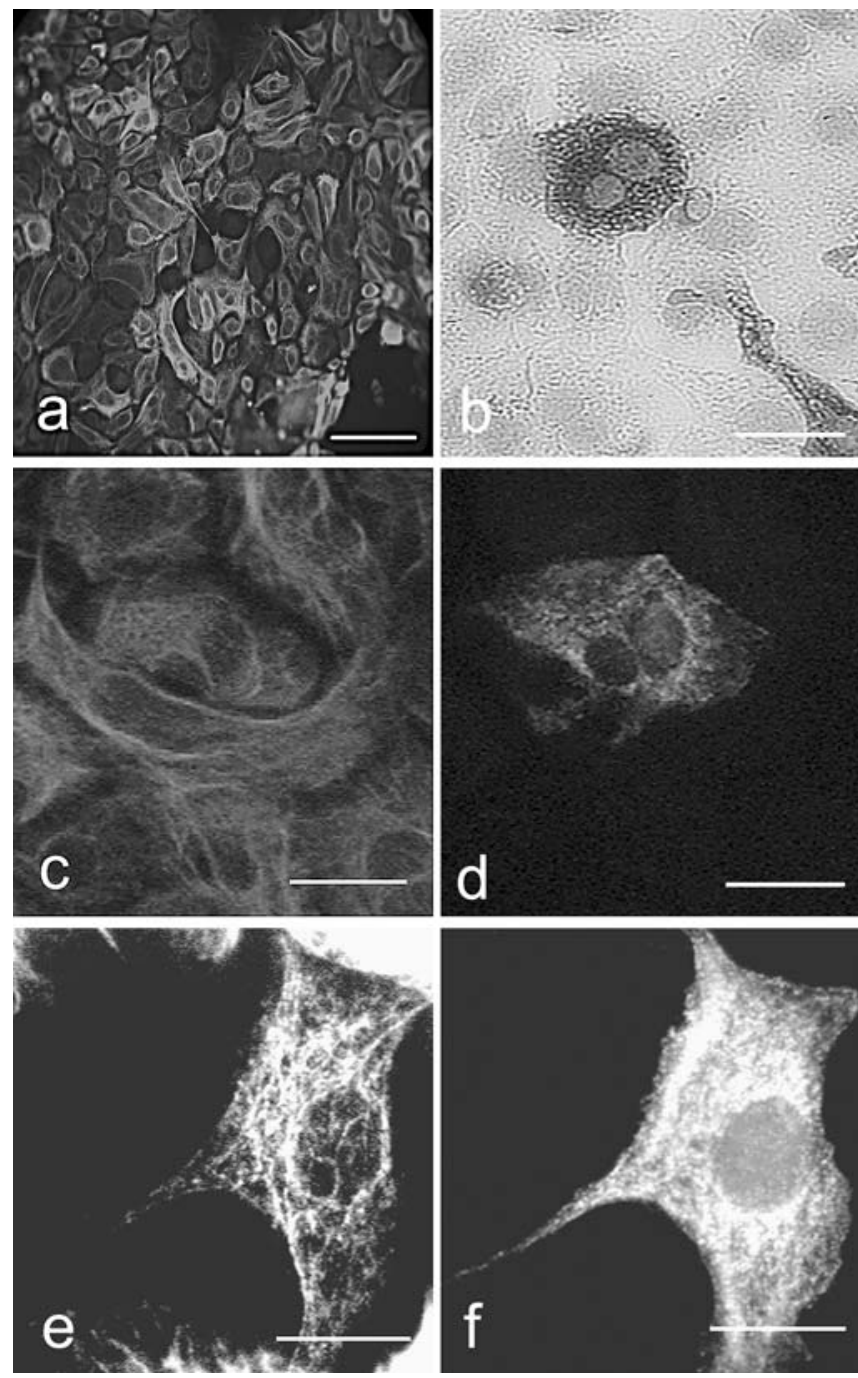

Fig. 1 Immunocytochemical analysis of CK20 (a, c, e) and insulin $(\mathbf{b}, \mathbf{d}, \mathbf{f})$ revealed the presence of cells positive for both markers in EGF and LIF-treated monolayers. The same cell, which is positive for both markers, is shown (c, $\mathbf{d}$ and $\mathbf{e}, \mathbf{f}$, respectively). A binuclear insulin-positive cell $(\mathbf{b}, \mathbf{d})$ is shown in a culture treated with EGF and LIF. Under normal conditions, binuclearity is a feature of the exocrine (acinar) cells. Bar $=20 \mu \mathrm{m}(\mathbf{a}) ; 10 \mu \mathrm{m}(\mathbf{b}-\mathbf{d}) ; 5 \mu \mathrm{m}(\mathbf{e}-\mathbf{f})$

in the absence of growth factors there were only $0.4 \pm 0.1 \%$ insulin-positive cells. As a direct measure of insulinpositive cell number, we counted the absolute number of insulin-positive cells per culture well (Fig. 2e). We found that EGF and LIF induced a 60-fold increase against control cultures. In cultures pretreated with alloxan, there were $0.6 \pm 0.1 \%$ and $0.5 \pm 0.1 \%$ insulin-positive cells in the presence of EGF and LIF, respectively, which was not significantly different from controls $(p>0.05)$.

Analysis by double immunofluorescence staining showed that most of these insulin-positive cells also expressed other beta cell markers, including proinsulin C-peptide-I, the transcription factor Pdx-1 (Fig. 3), and the glucose transporter GLUT-2 (not shown). Of all cells that express insulin, approximately 95\% coexpress Pdx $-1,95 \%$ coexpress C-peptide and 65\% coexpress GLUT-2. Immunore- 

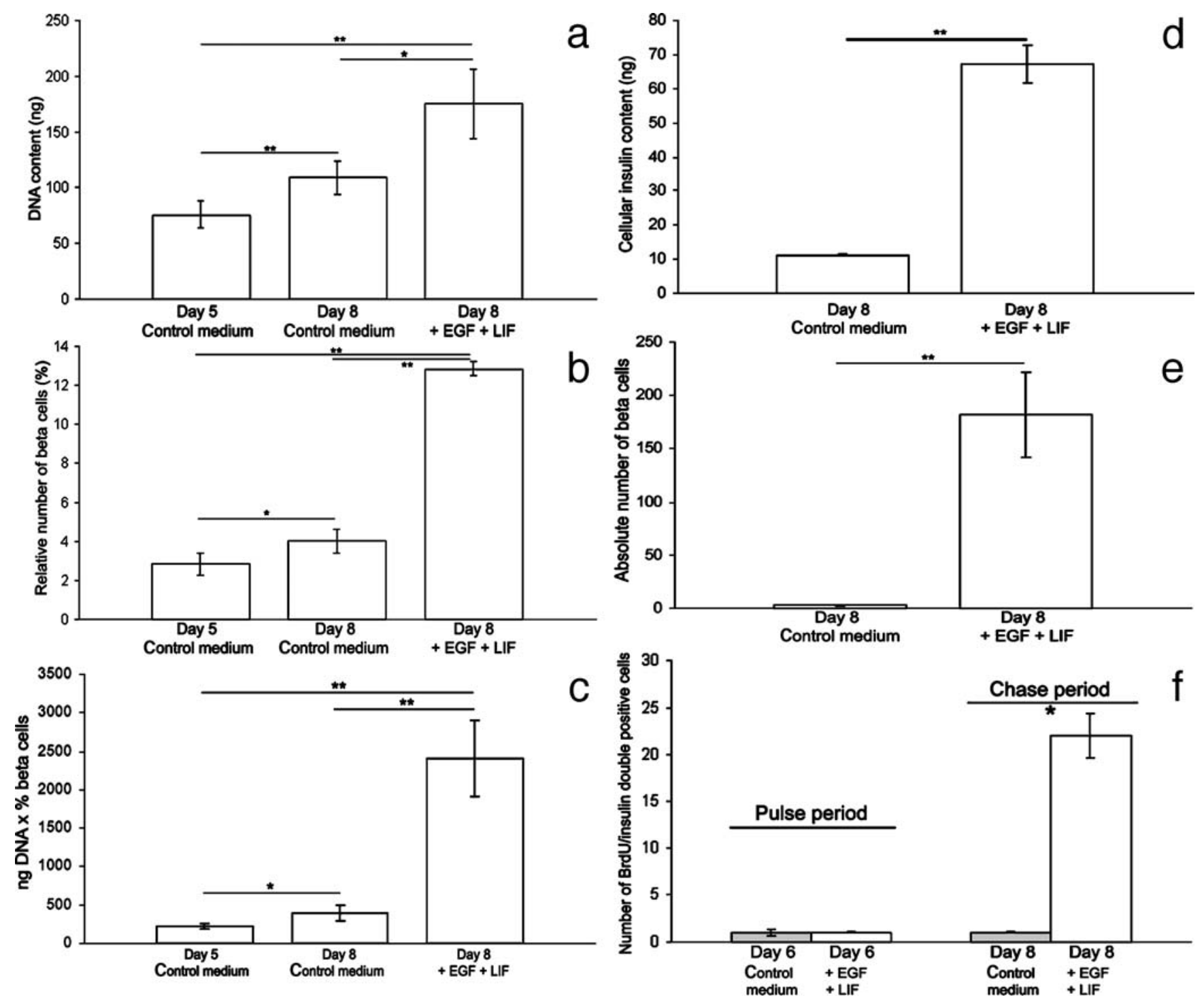

Fig. 2 The effect of the growth factors was analysed by DNA content measurement (a), \% insulin-positive cells (b), multiplication of both parameters to estimate total beta cell number (c), cellular insulin content (d) and counts of absolute beta cell number per well

activity for C-peptide excludes the possibility that insulin uptake from the medium explained the increased frequency of insulin-immunoreactive cells. Furthermore, insulin was not added to the medium. The same expression pattern was found irrespectively of whether the cells had been pretreated with alloxan or not. Immuno-electron microscopy revealed cells containing insulin immunoreactive cytoplasmic granules (Fig. 4). Some of these granules had the typical morphological appearance seen in normal beta cells, but atypical granules with insulin immunoreactivity were also present.

In the EGF+LIF-treated cultures, we noted that approximately $10 \%$ of the insulin-positive cells were immunoreactive for CK20, with a somewhat lower staining intensity than insulin-negative cells (Fig. 1c-f). Coexpression of insulin and CK20 was rarely observed in

in alloxan pre-treated cultures $(\mathbf{e})(n=7)$. f Results from BrdU labelling experiments: number of BrdU-labelled insulin-positive cells during the pulse $(24 \mathrm{~h})$ and the chase $(48 \mathrm{~h})$ period $(n=4)$. ${ }^{*} p<0.05 ; * * p<0.01$

control cultures, where no growth factors were added; it was also not seen in the starting material. This coexpression suggests a phenotypic transition from exocrine to insulin-positive cells. Strikingly, we also observed insulin and CK20-double-positive cells that were binuclear (Fig. 1c, d). Binuclear insulin-positive cells were rarely seen in control cultures and were absent at the start, but they were frequently seen in EGF+LIF-treated cultures, where they accounted for $6.2 \pm 0.47 \%(n=7)$ of all insulinpositive cells. Since binuclearity is a characteristic of the majority of acinar exocrine cells [13], these observations are another indication that a transition from exocrine cells to insulin-positive cells occurred.

In some experiments we added nicotinamide to the medium to look, using immunocytochemistry, for the presence of transitional cells containing acinar cell markers 

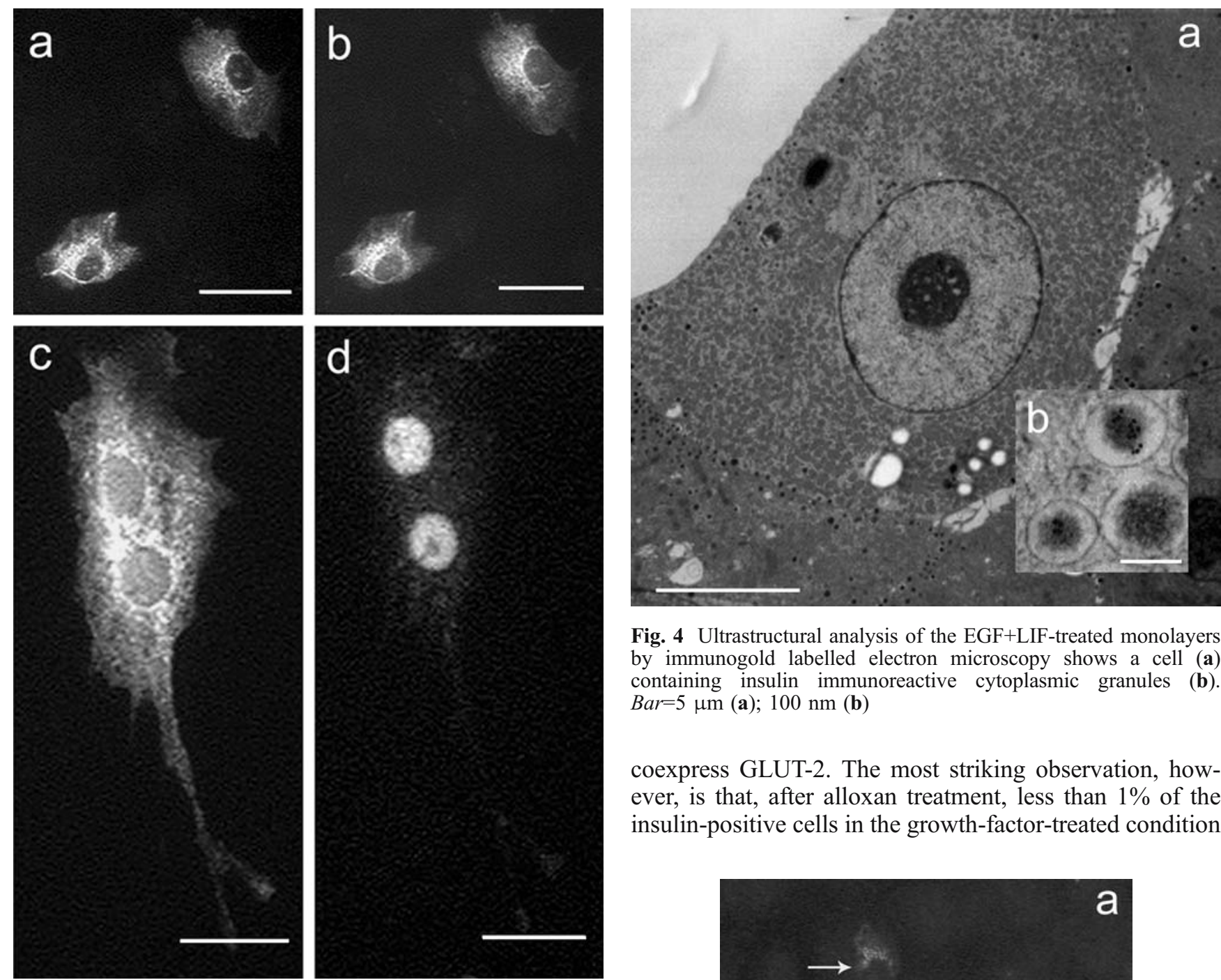

Fig. 4 Ultrastructural analysis of the EGF+LIF-treated monolayers by immunogold labelled electron microscopy shows a cell (a) containing insulin immunoreactive cytoplasmic granules (b). Bar $=5 \mu \mathrm{m}(\mathbf{a}) ; 100 \mathrm{~nm}(\mathbf{b})$

coexpress GLUT-2. The most striking observation, however, is that, after alloxan treatment, less than $1 \%$ of the insulin-positive cells in the growth-factor-treated condition

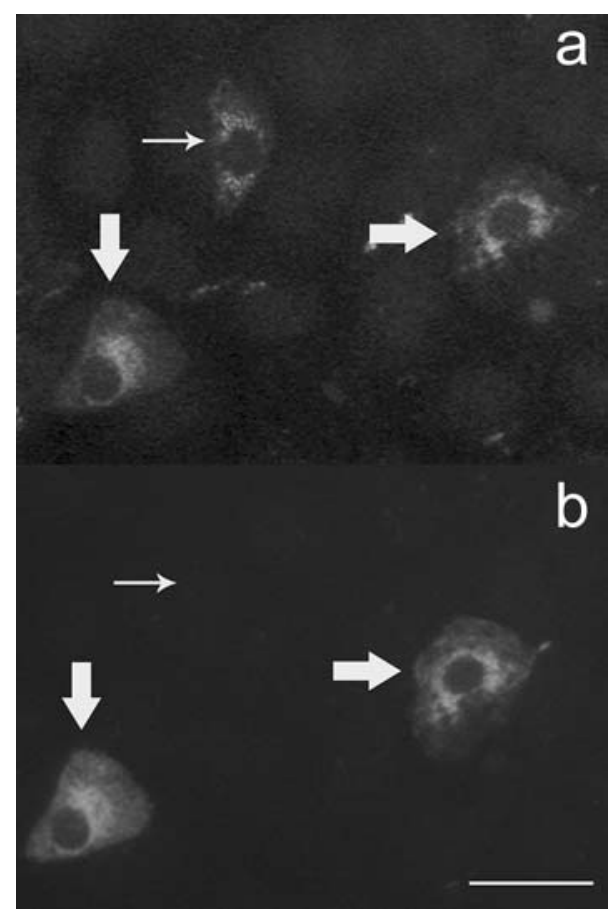

Fig. 3 Immunocytochemical analysis of expression of beta-cellspecific protein markers revealed double-positive cells for insulin (a, c) and C-peptide-I (b) or Pdx-1 (d) in monolayers treated with EGF+LIF. The same cell that is positive for both markers is shown (a, b and c, d, respectively). Bar $=10 \mu \mathrm{m}$

and insulin. We previously showed that acinar exocrine cells lose their functional characteristics like amylase during the first days of culture and that this can be prevented or reverted by nicotinamide [13]. When nicotinamide $(10 \mathrm{mmol} / \mathrm{l})$ was added to the medium of the growthfactor-treated cultures we did indeed find cells that were immunoreactive for both amylase and insulin (Fig. 5). Such double-positive cells were absent in control cultures. This is another indication that transdifferentiation from the original acinar exocrine cells into endocrine cells had occurred.

Some insulin-positive cells showed signs of immaturity as only $60 \%$ of the insulin-positive cells were also positive for islet amyloid polypeptide (IAPP), while almost all islet-derived beta cells expressed IAPP (data not shown). We already mentioned that $35 \%$ of the insulin-positive cells found in the growth-factor-treated cultures did not

Fig. 5 Immunocytochemical staining of nicotinamide-treated EGF and LIF-treated monolayers for amylase (a) and insulin (b). The thick arrows indicate cells which are positive for both markers. The thin arrows point to amylase-positive cells that are negative for insulin. Bar $=10 \mu \mathrm{m}$ 
were positive for the secretory marker chromogranin A (Fig. 6). Chromogranin-positive cells were observed in these cultures, but most of them were insulin-negative. In the growth-factor-treated group that was not pretreated with alloxan, approximately $35 \%$ of the insulin-positive cells expressed chromogranin A.

Analysis of BrdU incorporation in insulin-positive cells showed that less than $0.1 \%$ of insulin-positive cells were BrdU-labelled after a pulse of $1 \mathrm{~h}$. This makes it highly unlikely that binuclearity in these cells would have resulted from arrested nuclear division in mitotic beta cells, or that the increase in beta cell number would have resulted from proliferation of contaminating beta cells.

A BrdU pulse-chase experiment over a 72-h period (a pulse period of $24 \mathrm{~h}$ and a chase of $48 \mathrm{~h}$ ) revealed a significant increase in BrdU-labelled beta cells in the presence of EGF and LIF during the chase period (Fig. 2f). This increase can only be explained by the differentiation of proliferating exocrine cells into nonproliferating beta cells. Of the CK20-positive cells, $3.2 \pm 0.6 \%$ were labelled

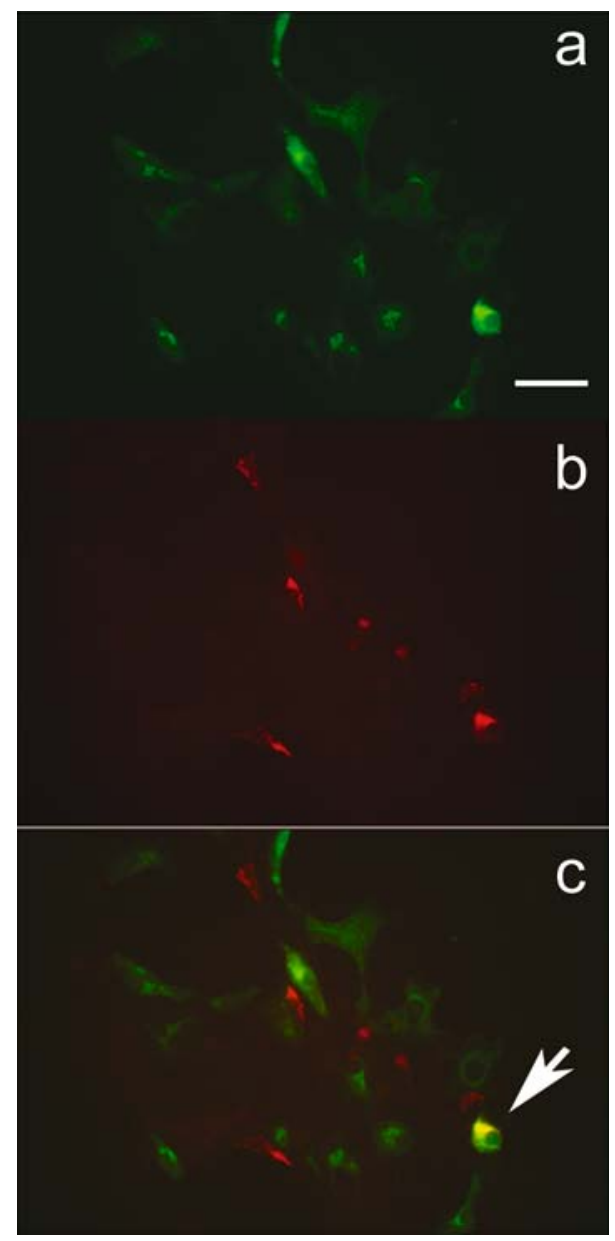

Fig. 6 Immunocytochemical analysis of insulin (a) and chromogranin A (b), with the combined picture (c). In growth-factor-treated cultures that were pre-treated with alloxan the majority of the insulin-positive cells were negative for the secretory marker chromogranin A. The arrow (c) indicates a cell positive for both markers. Bar $=10 \mu \mathrm{m}$

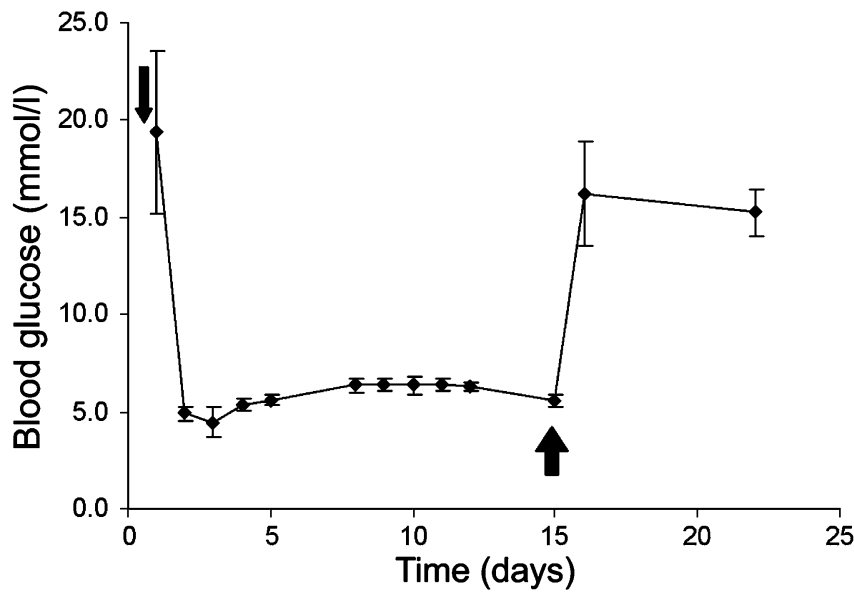

Fig. 7 Blood glycaemia in alloxan-diabetic nude mice transplanted with EGF- and LIF-treated pancreatic exocrine cells. Alloxan injection (i.v.) was given on day 1, $3 \mathrm{~h}$ prior to transplantation (thin arrow). Nephrectomy was performed on day 15 after transplantation (thick arrow). Untransplanted diabetic mice were hyperglycaemic $(>16.5 \mathrm{mmol} / \mathrm{l})$ at all time points (data not shown) $(n=4)$. Values shown are means \pm SEM

after the pulse and $10.1 \pm 1.0 \%$ were labelled after the chase.

Insulin secretion studies were done over $4 \mathrm{~h}$ in culture. Compared to their basal secretion in $2.5 \mathrm{mmol} / 1$ glucose, stimulation by $20 \mathrm{mmol} / \mathrm{l}$ glucose gave a fourfold increase in secreted insulin, namely from $1.2 \pm 0.03$ to $4.8 \pm 0.02 \mu \mathrm{g} / \mathrm{l}$, respectively.

Measurement of total cellular insulin content showed that control conditions contained $11.2 \pm 0.2 \mathrm{ng}$ insulin per well, whereas EGF and LIF-treated conditions contained $67.3 \pm 5.5 \mathrm{ng}$ insulin per well, which represents a sixfold increase $(n=3)$ (Fig. 2d).

We transplanted detached monolayers treated with LIF and EGF into alloxan-treated nude mice. Mice treated with $70 \mathrm{mg} / \mathrm{kg}$ alloxan remain permanently hyperglycaemic [8]. Engraftment resulted in normalisation of blood glycaemia, which was retained for at least 14 days, but promptly reverted to hyperglycaemia when the graft-bearing kidney was removed (Fig. 7). This demonstrates that the beta cells obtained in vitro by treatment with LIF and EGF are able to control blood glycaemia in vivo. Histological inspection revealed the presence of numerous insulin-immunoreactive cells at the site of implantation (Fig. 8).

\section{Discussion}

We previously showed that exocrine acinar cells lose their differentiated characteristics like amylase and other zymogens within 4 days of suspension culture and start to express ductal and embryonic characteristics like CK20, the combination of Pdx-1 and Ptf1-p48 transcription factors, the neuroendocrine markers PGP9.5 and the CCKB gastrin receptor [13, 14]. In the presence of dexamethasone, we showed that these cells can transdifferentiate into hepatocyte-like cells [15]. For the present 
Fig. 8 Immunohistochemical analysis of the graft, retrieved by nephrectomy on day 15 , revealed the presence of insulin immunoreactive cells (arrows). The cells were spread out as a thin layer, just beneath the kidney capsule. A light haematoxylin counterstaining was performed in this section

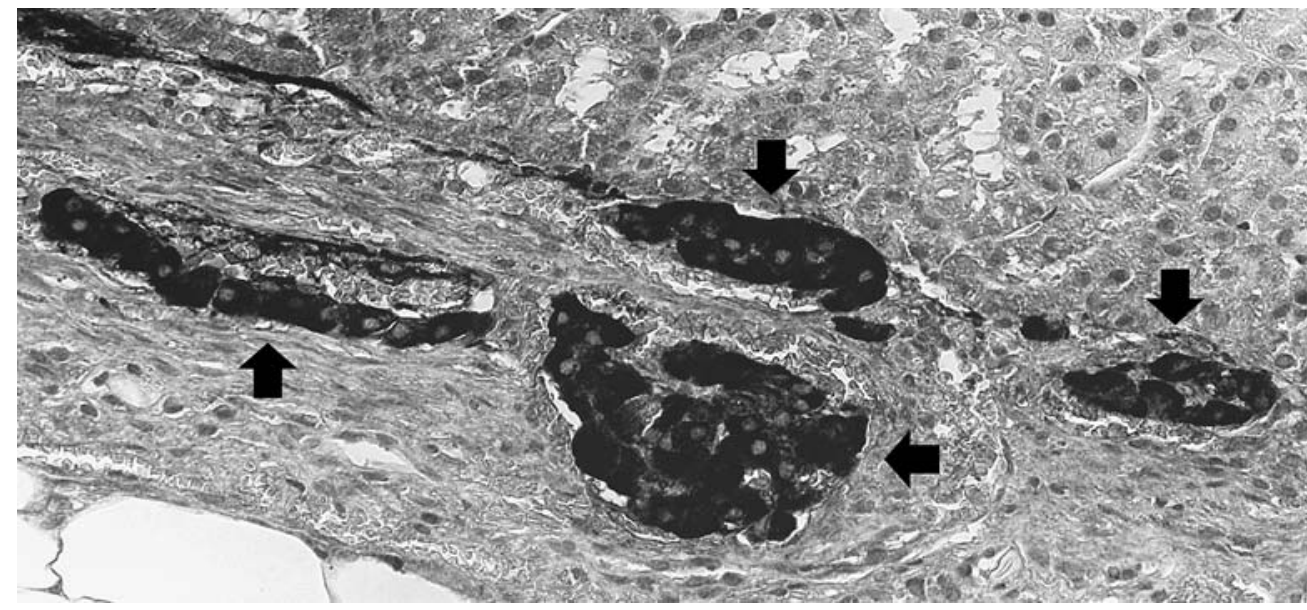

study these cells were cultured as monolayers attached to plastic, in the presence of low serum concentration $(1 \%$ FBS) and tested for the effect of a combination of LIF and EGF. These factors are known to control the differentiation of adult and embryonic neural stem cells [25]. In our model of dedifferentiated exocrine cells, this combination was found to stimulate cell proliferation as evidenced by a significant increase in total DNA and a larger area occupied by the monolayers. The combination of LIF and EGF also resulted in an approximately sixfold increase in the percentage of insulin-positive cells and a sixfold increase in insulin content. Combined with the observed increase in DNA, this gives approximately an 11-fold increase in beta cell mass. There were very few BrdU-labelled beta cells so that the observed increase in their number within a period of 3 days must be attributed to the differentiation of precursor cells, or neogenesis. Indeed, a BrdU pulse-chase experiment was able to confirm this. The very significant increase in BrdU-labelled insulin-positive cells after the chase period (when BrdU was no longer available) demonstrates that insulin-negative cells that had incorporated $\mathrm{BrdU}$ at the time of the pulse had differentiated into insulin-positive cells. Furthermore, when contaminating beta cells were depleted from the starting material prior to generation of the monolayers, culture in the presence of EGF and LIF resulted in the reappearance of insulinpositive cells within 3 days. These data clearly demonstrate neogenesis of insulin-producing cells.

The majority of the newly formed insulin-containing cells could be considered as mature beta cells since they expressed other phenotypic characteristics of beta cells, such as the insulin-transactivating transcription factor Pdx-1, the beta-cell-specific glucose transporter GLUT-2, and the C-peptide-I component of unprocessed proinsulin. They also contained insulin-immunoreactive granules, as shown by electron microscopy. The beta cells present in the culture were glucose responsive since there was a fourfold increase in insulin secretion upon glucose stimulation, and in vivo they were able to restore normoglycaemia in diabetic mice. However, indications remain that not all the cells are fully mature, since a significant part of the insulin-expressing cells did not coexpress IAPP or chromogranin A. These latter markers are considered as maturity markers in fetal islets [26].

There were two phenotypic indications that the exocrine cells served as precursor cells of the newly formed beta cells. First, CK20 immunoreactivity was noted in part of the insulin-positive cells. We have shown before that beta cells containing CK20 are only found in the fetal [19] and neonatal pancreas [18], and in adult pancreas when neogenesis has been induced by duct-ligation [27]. Thus, CK20 expression is a good indication of transition from CK20-positive exocrine cells to beta cells. Also, we were able to find cells coexpressing the acinar cell marker amylase with insulin suggesting a transition from acinar exocrine to endocrine phenotype. Second, binuclearity was noted in part of the insulin-positive cells. Binuclearity is a characteristic of acinar exocrine cells, and is not observed in normal rat beta cells [13, unpublished observations]. This is another indication that transition from exocrine cells to beta cells had occurred. It is unlikely that binuclear beta cells would represent dividing cells blocked before cytokinesis, since there was very little beta cell mitotic activity (BrdU incorporation). We cannot exclude cell fusion between beta cells, although this would rather lead to a decrease in beta cell number instead of the observed increase. We have unpublished observations suggesting that mononucleated insulin-positive cells could indeed arise from binucleated (exocrine) cells by a kind of delayed cytokinesis or cleavage process. Somatic cell cleavage or reduction-division has been demonstrated indirectly from tetraploid hybrid cells, but the mechanism has not yet been characterised [28].

Observations from previous in vivo studies suggest the existence of acinar-islet transitional cells $[16,29,30]$. It has also been demonstrated that the acinar exocrine cell line AR42J can transdifferentiate in vitro into the beta cell phenotype [31] or into hepatocytes [32]. We recently found that normal acinar cells can transdifferentiate into hepatocytes [15] and in the present study we provide evidence for a transdifferentiation into beta cells. Very recently, a "spontaneous" transdifferentiation of acinar to insulin-expressing cells has also been reported by others in a primary culture model [33]. 
EGF and other EGF-family members have been implicated in the regulation of embryonic development as well as regeneration of the endocrine pancreas. EGF stimulates proliferation of the undifferentiated pancreatic precursor cells in vitro [34]. In transgenic mice lacking functional EGF receptors, islet morphogenesis is impaired and beta cell differentiation is delayed [35]. Betacellulin, a growth factor which also operates via the EGF receptor, was found to promote islet regeneration in subtotally pancreatectomised rats [36] and in alloxan-diabetic mice [37]. In combination with gastrin hormone, EGF was shown to stimulate beta cell regeneration in alloxandiabetic mice [8].

LIF is a pleiotropic cytokine for which a function in pancreatic development has so far not been described. It is a well-known regulator of stem cell proliferation and differentiation and is widely used to prevent differentiation of embryonic stem cells. There exist a number of similarities between embryonic development of neural cells and of pancreatic endocrine cells with respect to the transcription factors that control their specification. For example basic helix-loop-helix factors like neurogenin-3 and beta-2/NeuroD are involved in embryonic neurogenesis and pancreatic endocrinogenesis [5]. It can therefore be expected that extrinsic signals that are known to control neural development may also be involved in pancreatic tissue development and possibly also in regeneration. LIF and EGF have been reported to act as signals that regulate the differentiation of neurons and glial cells in embryos [25]. In astrocyte progenitors EGF increases the competence to interpret LIF as an astrocyte-inducing signal via increased STAT3 phosphorylation [25]. LIF is also considered a key signal for injury-induced neurogenesis in the adult [38]. EGF receptor is known to be broadly expressed by the pancreatic cell types, however nothing is known of LIF receptor expression. In our cultures we found that the exocrine cells express the LIF receptor and gp-130 (unpublished observations).

In conclusion, we report a short-term culture model, in which beta cell neogenesis can be induced from exocrine cells by the combination of two soluble factors in the medium, namely EGF and LIF. The newly generated insulin-producing cells were glucose-responsive and able to normalise diabetic mice after transplantation. If this can be applied to human cells, it will provide a way to overcome the problem of insufficient donor beta cells, offering an important advancement in the treatment of diabetes by islet transplantation. This model could allow the molecular mechanism of respecification of adult cells to be unravelled.

Acknowledgements This work was supported by a Focused Research Grant from EFSD/JDRF/Novo Nordisk. Additional support was obtained from the Fund for Scientific Research Flanders (FWO grant G001502). We are grateful to Dr Daniël Pipeleers for general and logistic support. The authors wish to thank Emmy De Blay, William Rabiot and Yves Guns for expert technical assistance. L. Baeyens is a research fellow of the Institute of Innovation by Science and Technology flanders.

\section{References}

1. Shapiro AM, Lakey JR, Ryan EA et al (2000) Islet transplantation in seven patients with type 1 diabetes mellitus using a glucocorticoid-free immunosuppressive regimen. N Engl J Med 343:230-238

2. Yamaoka T (2002) Regeneration therapy of pancreatic beta cells: towards a cure for diabetes? Biochem Biophys Res Commun 296:1039-1043

3. Bouwens L, Kloppel G (1996) Islet cell neogenesis in the pancreas. Virchows Arch 427:553-560

4. Dor Y, Brown J, Martinez OI, Melton DA (2004) Adult pancreatic beta-cells are formed by self-duplication rather than stem-cell differentiation. Nature 429:41-46

5. Edlund H (2002) Pancreatic organogenesis-developmental mechanisms and implications for therapy. Nat Rev Genet 3:524-532

6. Bonner-Weir S, Baxter LA, Schuppin GT, Smith FE (1993) A second pathway for regeneration of adult exocrine and endocrine pancreas. A possible recapitulation of embryonic development. Diabetes 42:1715-1720

7. Rooman I, Lardon J, Bouwens L (2002) Gastrin stimulates beta-cell neogenesis and increases islet mass from transdifferentiated but not from normal exocrine pancreas tissue. Diabetes 51:686-690

8. Rooman I, Bouwens L (2004) Combined gastrin and epidermal growth factor treatment induces islet regeneration and restores normoglycemia in C57B16-J mice treated with alloxan. Diabetologia 47:259-265

9. Bonner-Weir S, Taneja M, Weir GC et al (2000) In vitro cultivation of human islets from expanded ductal tissue. Proc Natl Acad Sci USA 97:7999-8004

10. Gao R, Ustinov J, Pulkkinen MA, Lundin K, Korsgren O, Otonkoski T (2003) Characterization of endocrine progenitor cells and critical factors for their differentiation in human adult pancreatic cell culture. Diabetes 52:2007-2015

11. Ramiya VK, Maraist M, Arfors KE, Schatz DA, Peck AB, Cornelius JG (2000) Reversal of insulin-dependent diabetes using islets generated in vitro from pancreatic stem cells. Nat Med 6:278-282

12. Kodama S, Kuhtreiber W, Fujimura S, Dale EA, Faustman DL (2003) Islet regeneration during reversal of autoimmune diabetes in NOD mice. Science 302:1223-1227

13. Rooman I, Heremans Y, Heimberg H, Bouwens L (2000) Modulation of rat pancreatic acinoductal transdifferentiation and expression of PDX-1 in vitro. Diabetologia 43:907-914

14. Rooman I, Lardon J, Schuit F, Flamez D, Bouwens L (2001) Mitogenic effect of gastrin and expression of gastrin receptors by duct-like cells of rat pancreas. Gastroenterology 121:940 949

15. Lardon J, De Breuck S, Rooman I et al (2004) Plasticity in the adult rat pancreas: transdifferentiation of acinar exocrine cells to hepatocytes in primary culture. Hepatology 39:1499-1507

16. Lardon J, Huyens N, Rooman I, Bouwens L (2004) Exocrine cell transdifferentiation in dexamethason-treated rat pancreas. Virchows Arch 444:61-65

17. Loontiens FG, Regenfuss P, Zechel A, Dumortier L, Clegg RM (1990) Binding characteristics of Hoechst 33258 with calf thymus DNA, poly[d(A-T)], and d(CCGGAATTCCGG): multiple stoichiometries and determination of tight binding with a wide spectrum of site affinities. Biochemistry 29:9029-9039

18. Bouwens L, Wang RN, De Blay E, Pipeleers DG, Kloppel G (1994) Cytokeratins as markers of ductal cell differentiation and islet neogenesis in the neonatal rat pancreas. Diabetes 43:1279-1283

19. Bouwens L, De Blay E (1996) Islet morphogenesis and stem cell markers in rat pancreas. J Histochem Cytochem 44:947951

20. Blume N, Petersen JS, Andersen LC et al (1992) Immature transformed rat islet beta cells differentially express C-peptides derived from the genes coding for insulin I and II as well as a transfected human insulin gene. Mol Endocrinol 6:299-307 
21. In't Veld PA, Pipeleers DG (1988) In situ analysis of pancreatic islets in rats developing diabetes. Appearance of nonendocrine cells with surface MHC class II antigens and cytoplasmic insulin immunoreactivity. J Clin Invest 82:1123-1128

22. Pipeleers DG, In’t Veld PA, Van De Winkel M, Maes E, Schuit FC, Gepts W (1985) A new in vitro model for the study of pancreatic A and B cells. Endocrinol 117:806-816

23. Lobner K, Steinbrenner H, Roberts GA et al (2002) Different regulated expression of the tyrosine phosphatase-like proteins IA-2 and phogrin by glucose and insulin in pancreatic islets: relationship to development of insulin secretory responses in early life. Diabetes 51:2982-2988

24. Keymeulen B, Korbutt G, De Paepe M, Gorus F, Kloppel G, Pipeleers DG (1996) Longterm metabolic control by rat islet grafts depends on the composition of the implant. Diabetes 45:1814-1821

25. Viti J, Feathers A, Phillips J, Lillien L (2003) Epidermal growth factor receptors control competence to interpret leukemia inhibitory factor as an astrocyte inducer in developing cortex. J Neurosci 15:3385-3393

26. Piper K, Brickwood S, Turnpenny LW et al (2004) Beta cell differentiation during early human pancreas development. J Endocrinol 181:11-23

27. Wang RN, Kloppel G, Bouwens L (1995) Duct- to islet-cell differentiation and islet growth in the pancreas of duct-ligated adult rats. Diabetologia 38:1405-1411

28. Wang X, Willenbring H, Akkari Y et al (2003) Cell fusion is the principal source of bone-marrow-derived hepatocytes. Nature 422:897-901

29. Gu D, Arnush M, Sarvetnick N (1997) Endocrine/exocrine intermediate cells in streptozotocin-treated Ins-IFN-g transgenic mice. Pancreas 15:2496-2501
30. Bertelli E, Bendayan M (1997) Intermediate endocrine-acinar pancreatic cells in duct ligation conditions. Am J Physiol 273: C1641-C1649

31. Mashima H, Ohnishi H, Wakabayashi K et al (1996) Betacellulin and activin A coordinately convert amylasesecreting pancreatic AR42J cells into insulin-secreting cells. J Clin Invest 97:1647-1654

32. Shen CN, Slack JM, Tosh D (2000) Molecular basis of transdifferentiation of pancreas to liver. Nat Cell Biol 2:879887

33. Song KH, Ko SH, Ahn YB et al (2004) In vitro transdifferentiation of adult pancreatic acinar cells into insulin-expressing cells. Biochem Biophys Res Commun 316:1094-1100

34. Cras-Meneur C, Elghazi L, Czernichow P, Scharfmann R (2001) Epidermal growth factor increases undifferentiated pancreatic embryonic cells in vitro: a balance between proliferation and differentiation. Diabetes 50:1571-1579

35. Miettinen PJ, Huotari M, Koivisto T et al (2000) Impaired migration and delayed differentiation of pancreatic islet cells in mice lacking EGF-receptors. Development 127:2617-2627

36. Li L, Seno M, Yamada H, Kojima I (2001) Promotion of betacell regeneration by betacellulin in ninety percent pancreatectomized rats. Endocrinology 142:5379-5385

37. Yamamoto K, Miyagawa J, Waguri M et al (2000) Recombinant human betacellulin promotes the neogenesis of beta-cells and ameliorates glucose intolerance in mice with diabetes induced by selective alloxan perfusion. Diabetes 49:2021-2027

38. Bauer S, Rasika S, Han J et al (2003) Leukemia inhibitory factor is a key signal for injury-induced neurogenesis in the adult mouse olfactory epithelium. J Neurosci 23:1792-1803 